\title{
Analyzing the Vehicle Insurance Ecosystem in Estonia using Actor-Network Theory
}

\author{
Andrew Adjah Sai \\ Lecturer and Researcher at Estonian Business School, Tallinn, Estonia \\ Anna Naroznaja \\ Partner at Plottera
}

Doi:10.19044/esj.2018.v14n26p45 URL:http://dx.doi.org/10.19044/esj.2018.v14n26p45

\begin{abstract}
This paper focuses on analyzing the vehicle insurance ecosystem in Estonia that integrated Actor Network Theory (ANT) as theoretical lens to investigate potential transformations in the said ecosystem and to gauge the influence of insurance-oriented telematics technology. The paper combined an interpretive approach applied to a case study method. The study offers insights which are useful to facilitate the alignment of insurance-oriented telematics technology and its practical implementation within social systems. This study is one of the first to examine insurance-oriented telematics technology as a socio-technical process in Estonia.
\end{abstract}

Keywords: Actor network theory, Estonia, insurance-oriented telematics technology

\section{Introduction}

The insurance industry is a heavily regulated and data-driven industry. The rise of what is known within the insurance circles as "Insurtech" promises to significantly disrupt traditional insurance practices (Lee \& Shin, 2017). However, this is especially due to the adoption of sensors worldwide which has a growing significant impact on different industries (Xu \& Li, 2014). Insurtech is a set of innovative business models, platforms that bring in a new customer experience by applying innovative technologies in the insurance world. Insurtech thrives under the bigger umbrella of the fintech industry. Fintech is an emerging financial services sector that includes third-party payment, money market funds (MMF), insurance products, risk management, authentication, and peer-to-peer (P2P) lending (Barberis, 2014, as cited in Shim and Shin, 2016). They noted that the financial sector has been relying on internet-based technology to bring new services to markets for some time. 
Also, they agreed that the offline industry is gradually integrating more and more with online technologies.

The traditional vehicle insurance calculation methodology was mostly based on general factors as vehicle characteristics and driver's sociodemographical data (Segovia-Vargas et al., 2015). However, the competition between insurance firms is increasing and many companies are trying to reduce costs; due to this, the Usage- Based-Insurance (UBI) was developed (Troncoso et al., 2007), which is based on innovative internet-based telematics technology. Telematics technology involves data collection, transmission, and analysis of data collected from a device installed in a motor vehicle. The technology generates usage-based driving information such as vehicle speed, acceleration, and location. Personal driving data is also generated which can serve as a basis for optimizing driving styles and other social facets. Several studies have been conducted about the efficiency of telematics technology and transport, for example the effective implementation of telematics solutions aimed in the streamlining and optimization of urban freight transport systems (Iwan, 2016). Consequently, another research about urban traffic speed and maximization of fuel economy (Zhang et al., 2015), particularly telematics solutions, have become more substantial in having a significant influence on vehicle pollution reduction (Walker \& Manson, 2014).

Actor Network Theory (ANT) is a socio-technical approach that researchers employ to gain a better understanding of social and technological developments in a social system. ANT focuses on the relationships between the human and non-human (Papadopoulos, 2007), and it evolved from the work of Michel Callon, John Law, and Bruno Latour (Graham \& Marvin, 2001). According to Latour (1999), to bypass the divide between nature and culture, ANT theorist should concentrate on the inclusion of non-humans into the social sphere and humans into the natural sphere. Therefore, this fundamental position has been supported by many scholars. For example, Pinch (1996) argued that technology goes through and through the social, while Bijker (1987) asserted that technology and society exist as a seamless web.

To understand the insurance ecosystem in Estonia, therefore, the interweaving of social and technological dimensions has become significant. An attempt has been made to show the insurance ecosystem through ANT. Using the ANT approach, all the factors (both human and non-human) influencing the insurance ecosystem in Estonia are seen as actors and a combination of all these in terms of networks. Consequently, the actor network illustration would help to visualize all the key players in the ecosystem and bring out their interconnections. It has been argued among scholars in this field that ANT theory provides a powerful tool to better reveal the complexities and dynamics of a technology driven industry. 
The Estonian insurance ecosystem has been thriving since reindependence in 1991. Traditional insurance practices have dominated the insurance industry. Consequently, the insurance industry, though heavily regulated in Estonia, has not employed insurance-oriented telematics technology. Records indicate that accident rates are on the high. At both individual ownership and firm levels, little can be done to regularize driver behaviour and to become more accurate in terms of premium pricing, among others.

The primary research question is "How can telematics-oriented technology form an actor network for re-configuring the Estonian insurance ecosystem?" For this case study, we employ actor network theory as a lens and interpretation tool. We first show the ecosystem without telematics technology, and the situation after telematics were brought into the picture and to substantiate the findings with data analyzed from actual tests conducted.

The following research questions guide this study:

1. Who are the focal actors in the Estonian insurance ecosystem and how have they done so far?

2. What are the implications of re-configuring the insurance ecosystem with telematics technology?

\section{Theoretical Framework}

\subsection{Telematics Technology}

Telematics technology as a concept has received little attention in both research and practice. The few studies conducted about "fintech" and new technologies such as "telematics" have not adequately defined the scope and parameters of its usage. However, some scholars have attempted to do so. For example, Nora and Minc in 1978 asserted that "telematics is not a distinct technology or technology standard" (Nora \& Minc, 1978). Other scholars described the combination of telecommunication and information processing, as predominantly referring to information and communications technology within road vehicles (Nijkamp et al., 1996; Van Der Laan et al., 1997). Husnjak, et al. (2015) posited that Global Positioning System (GPS) technology is used in car telematics together with other sensor devices to monitor driving distance, speed, and style. The influence of these same technologies and devices on driving behaviour has been confirmed by Ayuso, et al. (2014), regardless that there is no peer reviewed evidence about the effects of GPS and sensor devices on outcomes such as road injury.

Prior research in other contexts, using various research methods (Husnjak, Peraković, Forenbacher, \& Mumdziev, 2015), have highlighted the importance of telematics technology generated data for both the policyholder and insurance companies. Other studies highlighted include the observations of motor insurance pricing in India and the need for a radical innovation to 
disrupt the status quo (Rejikumar, 2013). Mihaela David reviewed theoretical concepts about non-life insurance pricing and noted that one of the major concerns for the insurance companies is the design of tariff structure that will fairly distribute the burden of claim among policyholders. He observed in that same study that the calculation of a differentiated premium within the insurance portfolio is almost non-existent such that a flat risk profile is assumed for the determination of reasonable insurance premiums (David, 2015). Marika Azzopardi et al also used a SWOT-analysis to navigate UsageBased Insurance and conventional rating methods for automotive covers and concluded that telematics enhances fleet management and mitigates risk (Azzopardi \& Cortis, 2013). A study in China, focused on risks in the proceedings of underwriting, established a scientific and practical model to enhance motor insurance underwriting risk management process (Chehui, Zhangjiwu, \& Zhangxingyang, 2011). One noteworthy study proved the value of telematics-based data in the risk selection process of an insurance company, where three models including a logistic regression, random forests, and artificial neural networks model are built and compared (Baecke, 2017). YuLuen Ma et al confirm that mileage, peak time travel as well as driving behavior such as braking or starting habits are highly correlated with accident rate. They also confirm that contextual driving factors such as speeding and relative speed are important risk factors (Ma et al., 2018). Another interesting study described a partnership between one of Italy's largest auto insurers (Unipol) and a systems integrator (Octo Telematics) that yielded a new and very profitable customer value proposition for the insurer based on customer's driving and risk profiles (Peppard et al., 2011).

\subsection{An Actor Network Theory (ANT) Perspective}

Young et al. (2010) have argued that ANT regards networks as dynamic processes, while other theories such as stakeholder theory, agency theory, and social network theory, among others, limited the focus on the interests of human participants in the network.

According to Callon (1986), translation and inscription are two crucial processes in ANT. He defined inscription as referring to the process of creating technical artifacts that ensure the protection of an actor's interests. Cressman (2009) also asserted that within ANT, translation is a concept that bridges gaps between the varied aspects that are combined in technology. Callon's four moments are applied widely in ANT research and is employed in this study. To Callon, op. cit., translation of an actor or actors into a network is achieved through four moments of translation: (1) problematisation, (2) interessement, (3) enrollment, and (4) mobilisation. In the first moment, focal actors define their interest based on the problem they face in achieving their goal, and they aim to establish themselves as an obligatory passage point (OPP) through 
which the other actors must pass. This is a situation that has to occur for all the actors to satisfy their interests (Callon, 1986). In the second moment, interessement, focal actors impose and stabilize other actors' identity. Focal actors attempt to define and interrelate the various roles taken up by other actors in enrollment, the third moment. In the final moment of translation, mobilisation, actors are persuaded that their interests are aligned with those of the focal actor, thereby avoiding betrayal and allowing the network to be maintained (Callon, 1986).

\subsection{Estonia - A Small Baltic Country with Big Technology Advancements}

Few studies have focused on the Estonian financial industry, not to speak of insurance industry. However, some studies exist on the social system of Estonia and technological change (Sai \& Boadi, 2017); ANT and urban planning and development in Tallinn (Pulk \& Murumägi, 2013). Sai et al. (2017) argued that Estonia has remained a giant in terms of technological advancements over the last few decades since re-independence in 1991 from the Soviet era. For 50 years, Estonia was under the Soviet regime. Sai, et al, op. cit., further argued that the changes occasioned in Estonia are partly a result of the social system being densely homogenous. The country is located in Eastern Europe and has a population of about 1.3 million people. The Estonian social system can be characterized as homophilous (Lazarfeld \& Merton, 1964, p. 23 as cited in Sai, et al, op cit.). Homophilous social systems tend toward system norms. They posited that interaction in such social systems is between people of similar backgrounds, while people and ideas that differ from the norm are seen as strange and undesirable. Even though Lazarfeld et al have argued that homophilous social systems are often less innovative, the case is not same with Estonia. Estonia has chalked major successes on various technology and country development indicators over a relatively short period of time. At the same time, while telematics technology has received wide acceptance in central and northern Europe, no such evidence exists about its use in Estonia. For example, Peppard et al., op. cit., have provided insights into the Italian case.

However, the total land area is $45,336 \mathrm{~km}^{2}$ (17,504 square miles) with a population density of about 30 inhabitants per $\mathrm{km}^{2}$ ( 75 inhabitants per square mile). Administratively, the country is divided into 15 counties, 213 administrative units, including 30 cities and 183 rural municipalities. The official language is Estonian. However, English, Russian, Finnish, and German are widely spoken as well. Tallinn is the capital city. Other principal cities in Estonia are becoming more and more urbanized, while the Estonian society is undergoing considerable change with increasing levels of stratification and distribution of family income (Sai \& Boadi, 2017). 


\section{Methodology}

The paper opted for qualitative methods and draws from the interpretive paradigm, as suggested by Dudovskiy (2018). The theoretical framework lies on actor network theory. The assumption behind actor network theory is that the process of interest alignment and associations are examined from the perspective of the network (Monteiro, et al., as cited in Pulk and Murumagi, 2013). In this sense, the role of the researcher is to examine and record the network's elements, investigate the way that aligned networks are created, and explore the stability and irreversibility of the network (Tsohou, 2012); treat all actors the same way irrespective of their human or non human nature. The study approach was inductive, which is suitable for case studies and actor network theory methods. According to Eisenhardt and Graebner (2007), case studies allow us to develop theory inductively by accommodating variable number of sources. In the paper, the researchers combined actor network theory with exploratory case study method. Exploratory case method was suitable as it aims to find answers to the questions of "what" or "who" (Dodovskiy, 2018). Conducting a case study research involves the use of some combination of different methods and procedures for collecting and analyzing data (Yin, 2009). Both the quantitative and qualitative methods can serve as the basic methods for carrying out the research and to describe in detail a social phenomenon. Data was sourced via primary and secondary sources. The primary data was collected from Estonian Telematics company, Plottera. The data assembled by telematics boxes were discretely installed on customer cars along with Global Positioning System (GPS) and General Packet Radio Service (GPRS) antennas, and they are connected to the CAN (Controller Area Network) bus of vehicles. Secondary data sources were sourced from Estonian Insurance Fund, published materials, and documents.

\section{Analyses}

\subsection{Observed Interaction between Actors in the Insurance Ecosystem}

Before analyzing the insurance ecosystem, it is imperative to identify the focal actor. In this paper, we identify insurance-oriented telematics technology as the focal actor. All other actors in the network are fully acknowledged. These include the Government (represented by the sector Minister); legislation (the Motor Insurance Act, 2014); The insurance regulators (Motor Insurance Fund (LKF)); Insurers; Vehicles and their Drivers. These actants are elaborated on in the ensuing section. Meanwhile, other representative actors, such as Motor Insurance Register Data and Police, are noted as well. 


\subsection{The Insurance Ecosystem without Telematics Technology}

Legislation: The current Motor Insurance Act of Estonia (amended) came into force fully in October 2014. This amended version repealed relevant sections of the Motor Insurance Act (RT I 2007, 55, 368) accordingly. This Act regulates insurance of civil liability arising from damage caused by the use of a vehicle in Estonia and it is compulsory per the Act. The compulsory aspect of the motor insurance is regulated by the provisions of the Laws of Obligations Act while automatic motor insurance is regulated by the provisions of the Administrative Procedure Act (Motor Insurance Act, 2014).

Regulator (The Motor Insurance Fund): In Estonia, a body charged with the responsibility over insurance oversight is the Estonian Traffic Insurance Fund. This non-profit body serves as a motor insurance guarantee, compensation entity, and is also responsible for the Estonian Green Card bureau. The LKF ensures the proper functioning of the motor insurance system by performing functions arising from the Motor Insurance Act and managing contracts entered into with the state and its articles of association, among other responsibilities. All insurers that offer motor insurance in Estonia are members of the LKF.

Insurer: The insurer is the principal contact for obtaining an insurance contact in Estonia. The Insurer is required by the Act to submit, to the Motor Insurance Register, data about contracts concluded and policies issued to insured entities; withdrawal from and cancellation of contracts; reports on insured events received and registration of same; decisions by the Insurer to compensate or refuse compensation for damages; recovery claims filed by the Insurer and vehicles destroyed due to insured events. Therefore, these duties are required under the Act.

Insured: The Insured is either an owner of a vehicle or an authorized user of a vehicle (Driver of vehicle).

Vehicle: All motor vehicles stated under the Act that are required to be covered under motor insurance.

Territorial Validity of Insurance Cover: Motor vehicles are registered by the state. Motor insurance cover is generally recognized regardless of the county (administrative zone or jurisdiction) where the motor vehicle was registered. That notwithstanding, an insured event is considered based on the location the event occurred and in which county the event occurred based on circumstances and prescriptions of the Act.

Notification of Insured Event: Insured events must be reported to the insurer of the person who caused damage or to the Insurer of an injured party, according to the Act. Further, the law specifies how issues of compensation and other notifications about insured events must be communicated, which includes via post and/or email. 
Access to Motor Insurance Register Data: Insurers are required by the Act, in the event of assessing the insured risk, and concluding a contract and its performance to access the Register via a Chief Officer.

Police: The same Act admonishes the Police to receive notification of insured events and also act as agents for enforcement of specific aspects of the Act on the field. The Police was extended to include all emergency services agencies and allied organizations that serve as first responders to accident events.

A schema illustrating the actors in the network without telematics technology is shown in Figure 1.

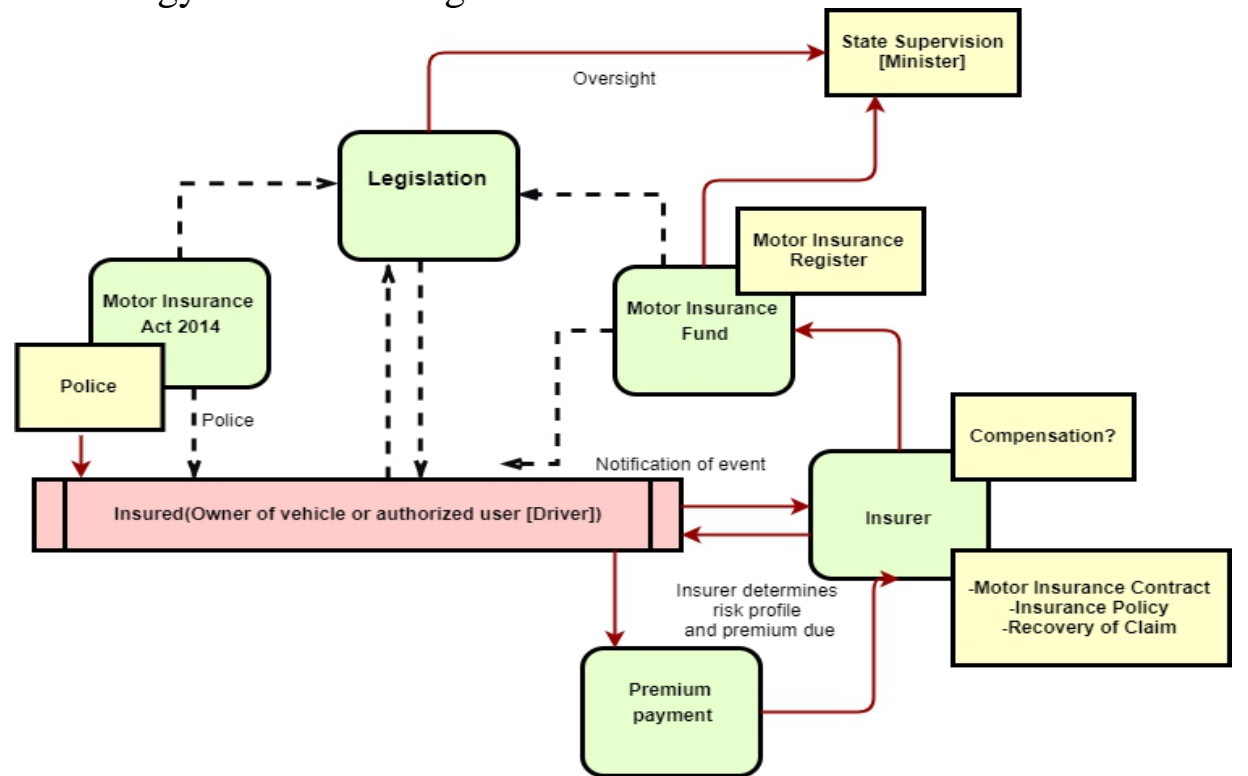

Figure 1. The Insurance ecosystem in Estonia without Telematics Technology. Source:

Authors

\subsection{First Moment of Translation: Problematization Phase}

As pointed out earlier in this paper, the insurance industry in Estonia is lagging behind other countries in terms of application of telematics-oriented vehicle insurance technologies to streamline the industry and, consequently, face significant problems as a result. This is the first phase in translation where the focal actor(s) define their interest in the problem they face in achieving their goal, and aim to establish themselves as an obligatory passage point (OPP) through which the other actors must pass (Callon, 1986). Some of the problems are discussed below:

\subsubsection{Vehicular Accidents in Estonia}

Between the period 2009 and 2016, the recorded vehicle accidents show that Mondays and Fridays recorded the highest number of vehicular 
accidents, at 30,786 accidents and 34,707 accidents respectively. The analyses were based on datasets from the Estonian Insurance Fund (LKF). Several factors account for this scale of accidents, some of which are discussed later in the paper. In terms of distribution by month, December and January recorded the highest number of accidents (19,227 and 17,673 respectively). For distribution by time of the day, 6:30am to 23:00 accounted for the most accidents, however peaking at 17:00. Figure 2 shows below the hourly distribution.

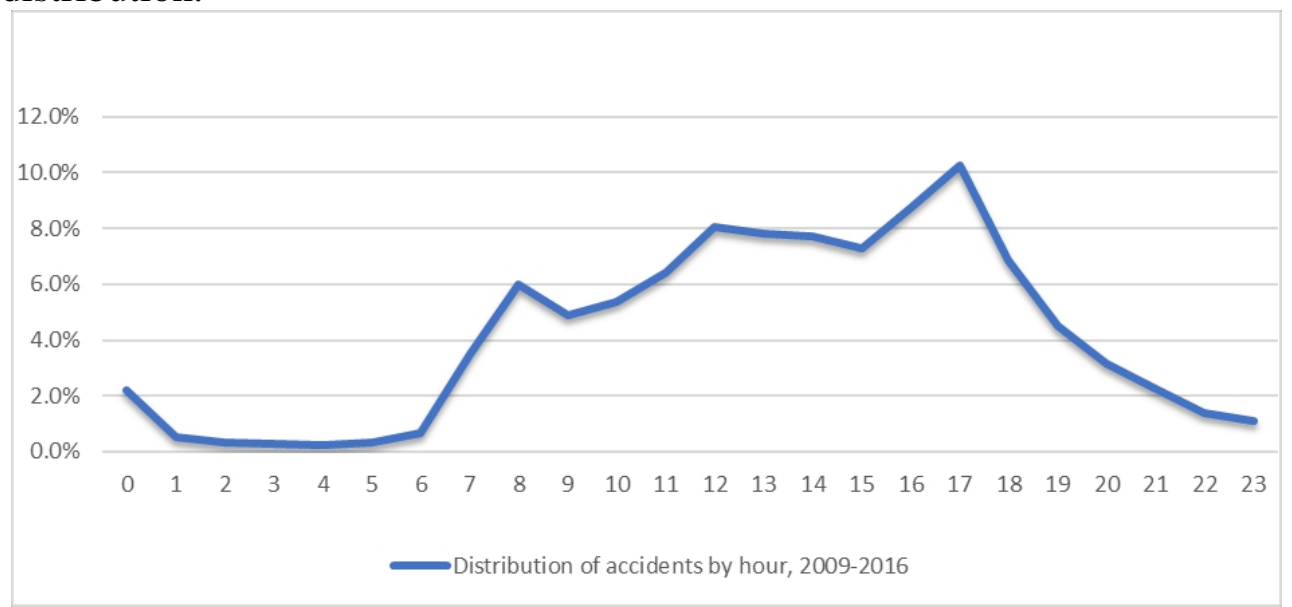

Figure 2. Distribution of accidents by hour, 2009-2016. Dataset from LKF Estonia

\subsubsection{Cost of Vehicular Accidents 2009 - 2016}

According to the LKF, an overwhelming amount of payments were made for insured events during the 2009 to 2016 period. Thus, most payments were made for cases at intersections, amounting to about 87.1 million euros. Other insured events occurred at same direction cases: parking related, opposite direction accidents, unspecified as well as special cases. Figure 3 summarizes this.

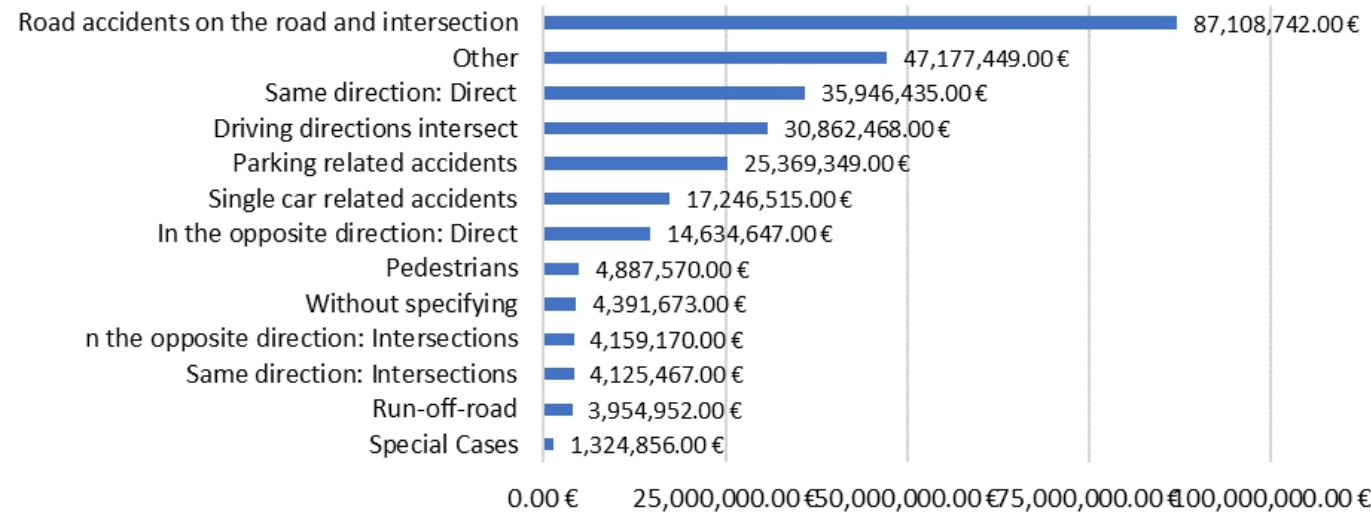

Figure 3. Payments for Accidents by type. Dataset from LKF Estonia 


\subsubsection{Number of Accidents by County}

Figure 4 shows accident distribution by counties. In the last six months of 2016, the highest occurrence of car accidents were registered in Harju county (10156 cases), while the smallest car damages were registered in Hiiu county -25 and Põlva county- 93 (LKF, 2017). The LKF further reports that most road accidents recorded in 2016 were caused by drivers, citing driver behavior as key triggers to these occurrences. These include over speeding, unsafe overtaking, and misjudgment of traffic and road conditions. The most frequent accidents were reported to have occurred at crossroads or intersections and parking lots in Tallinn, which is the capital city. The commonly cited trigger of these occurrences has been alcohol use and drugs (LKF, 2016).

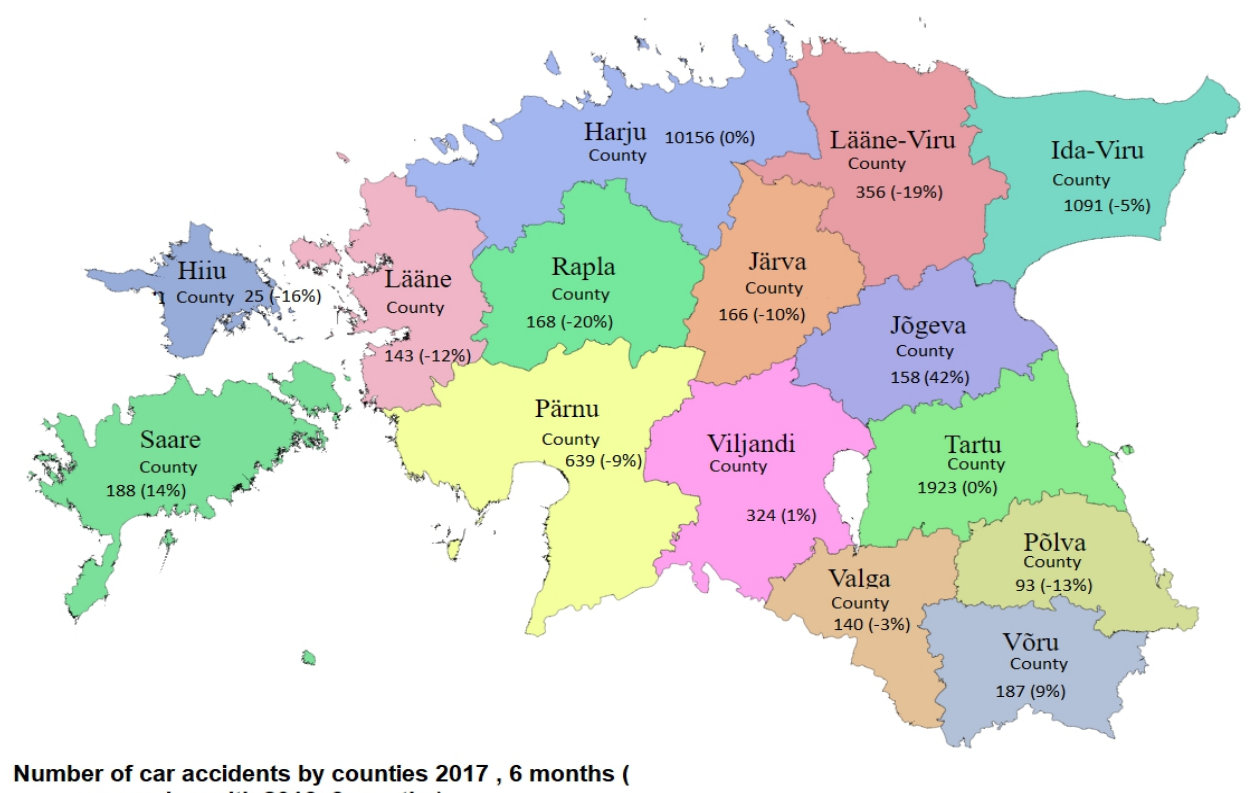
comparing with 2016, 6 months)

Figure 4. Event distribution by counties. Dataset from LKF Estonia

Subsequently, the most frequent accidents between the second half of 2016 and first half of 2017 occurred at crossroads and parking lots as earlier mentioned. The Rocca al Mare ring which is in the Mustamae district of the Harju country recorded the most damages from car accidents. 136 insured events amounting to losses of 0.18 million euros were made just from events at the said ring. For the same Harju county, Sõpruse pst., and Tammsaare crossroads, recorded 112 cases at 0.18 million euros losses. Ülemiste crossroad accounted for 109 cases, with pay-outs amounting to 0.14 million euros; Järvevana road, Tammsaare road and Pärnu mnt cross road accounted for 104 cases and losses by way of 0.19 million euros; Viru intersection accounted for 85 cases, with pay-out of 0.11 million euros. Others included 
Ülemiste keskus (155 cases, 0.16 million euros in pay-outs), Järve Keskus (109 cases, 0.1 million euros in pay-outs), Kristiine Keskus and Lasnamae Centrum (77 cases and 4 cases respectively, each paying out 0.06 million euros each).

The situation was not any different in the second largest city of Estonia, Tartu. Events were registered mostly at parking lots at Lõunakeskus in Tartu (112 cases, 0.14 euros paid out). The intersection at Riga in Tartu accounted for 114 cases at a cost of 0.16 million euros in pay-outs for insured events.

\subsection{Second Moment of Translation: Interessement Phase}

Callon (1986) has said that, at this phase, the focal actor convinces other actors to agree on and accept the definition.

In the first place, the current situation in the Estonian insurance ecosystem is fraught with several challenges as earlier discussed. Firstly, it has been established that driver behaviour is the main trigger for the countless losses made over the period. However, there is really no established mechanism to monitor such behaviour, given the current ecosystem. Secondly, the cases noted and reported by the LKF are collected and retrieved from data repositories, one of which is the Motor Insurance Data Register. Per the Motor Insurance Act, in the event of insured cases or their adjudication, as the case may be, a request has to be made to a principal officer at the Motor Insurance Data Registry. In addition, archived information together with reports from other actors, such as the Police, are released to affected parties, all within the remit of the law. In the event that these data are in some way adjusted either knowingly or unintentionally, the effect on a determination by a court of law is enormous on all parties. Thirdly, even though efforts have been made to identify risky zones, the data is not conclusive nor available. For example, there are fragmented data on risky zones, but there is no real-time information to address driver's needs.

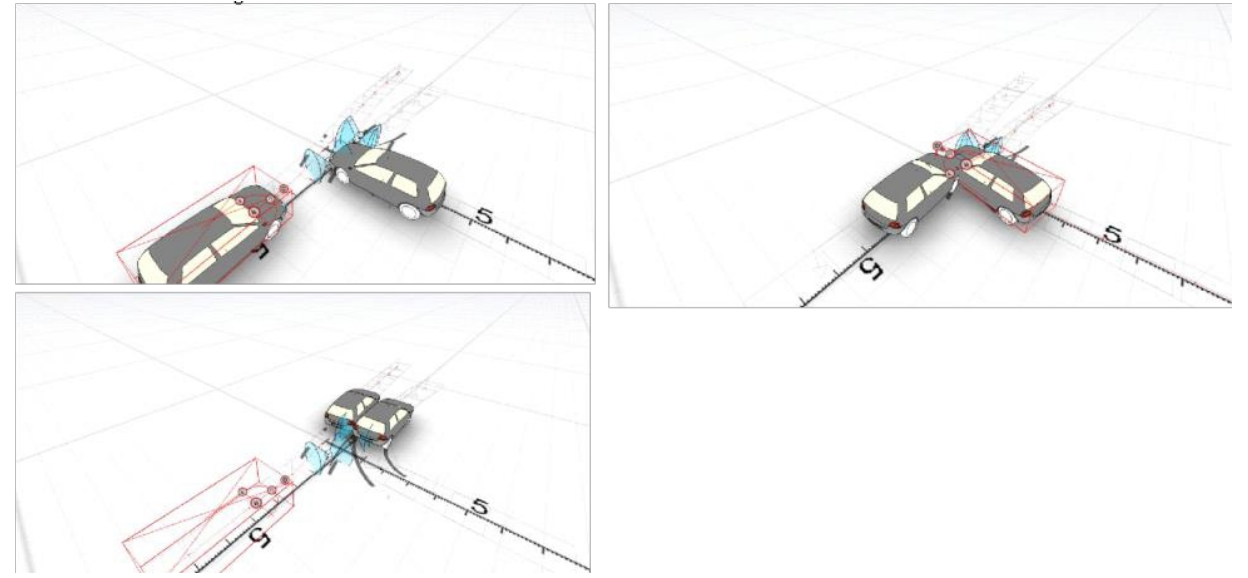

Figure 5. An example of real-time account of accident events generated from Plottera. 
Fourthly, the current situation prescribes a universal insurance coverage and territorial validity. This means notwithstanding the county where one subscribed to an insurance cover or location of insured event, risk premium calculation approaches are based on individual risk profiles (some of which may be inconclusive) and are not reflective of the actual situation.

\subsection{Third Moment of Translation: Enrollment Phase}

Callon, op cit., described this phase of translation as a "group of multilateral negotiation" (Callon, 1986). We put across what changes telematics technologies could make on the current ecosystem in Estonia in a bid to build a path to lead to enrolment from interessement, in the previous phase. The introduction of telematics could impact significantly on the future of the insurance ecosystem in Estonia. Firstly, telematic technology could be used to analyze vehicle initial registration points and where the vehicles were actually used. For instance, Hiiu county is a low-risk zone and, therefore, insurance premiums are lower. Vehicles are originally registered in Hiiu county at low fees and actually driven in high risk zone (for example, Tallinn in Harju county). Real-time data on driving locations can be shared with the Insurer and can serve as a basis for driver profiling and risk assessment and also the territorial validity of insurance cover. This could inure in a switch to usage-based mechanisms for premium calculations, among others and also classification schemes such as higher scores for driving within higher risk zones.

Further, traffic patterns at the moment are obtained from, again, fragmented online resources and maps. The use of telematics and its associated devices will provide real-time notifications to all parties in the ecosystem and would, therefore, reduce probable traffic jams. Furthermore, the work of the Police in the chain of events will become simpler as data generated from telematics technology actually showcases in graphical format how an accident occurred. It also shows how it reduces conflicts and their determination which sometimes is inaccurate (see Figure 5 above).

Telematics can also ease the work of the oversight body, the Government and its representative - the sector Minister. Accurate data about happenings on the ground can inform which portions of the current amended Act have to be revised, in addition to changing driving examination approaches to counter the gaps identified in the system. Laws about roads and their layouts in planning could be adjusted accordingly using such information. For example, most drunk and reckless driving cases have emanated from younger people within the population who are either inexperienced drivers or just run into these events as a result of youthful exuberance. This will mean channeling resources based on actual reports to a targeted audience within the public on extensive sensitization drives using 
images of actual occurrences. This approach from prior research has been known to be effective in communicating messages about such situations to ward off deviant behaviour.

\subsection{Fourth Moment of Translation: Mobilization Phase}

Latour (1987) argued that the outcome of successful negotiations is an actor-network characterized by aligned interests and when these interests have been successfully translated. This final phase in the translation endeavor is where the focal actor seeks to secure continued support to its goals and interest from the enrolled actors through multiple negotiations (Callon, op cit.). Figure 6 shows how heterogenous actors come together to form a network where Obligatory Passage Point (OPP) is telematics technology, through which other actors must pass. The OPP is the situation that has to occur for all the actors to satisfy their interests (Callon, op cit.).

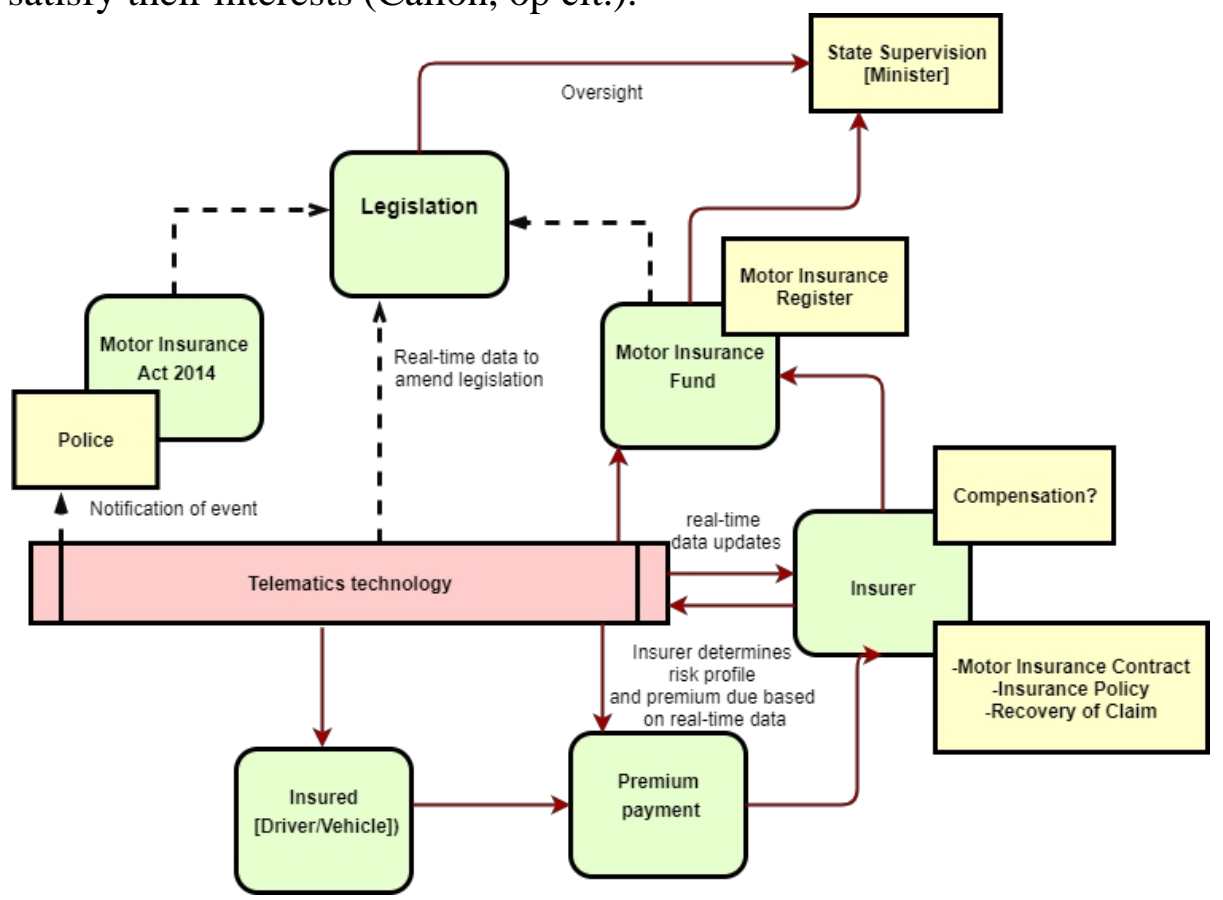

Figure 6. The Insurance ecosystem with Telematics Technology. Source: Authors

In an attempt to show this further and to establish the place of telematics technology in the Estonian insurance ecosystem, we selected an insurance solutions partner, Plottera (a software development company specializing in fleet management solutions based on global positioning systems (GPS) technology). We then established some criteria to select vehicles in Estonia, and we also tested the telematics technology under different conditions with the selected vehicles. The results are presented below. 


\subsection{Preparation for Tests}

The testing of telematics solutions for the insurance industry using Plottera began with the installation of GPS tackers on the selected vehicles. The devices are connected to the vehicles via OBD2, and the installation took up to ten minutes to complete. For purposes of better results, the tests were conducted at different times within the year and it varied from two to four months each.

\subsubsection{Solutions Partner}

In Figure 6 above, telematics technology is represented as one Obligatory Passage Point. Regardless of this, telematics technology implementation may require a solutions partner, software, and devices. The analytics partner is Plottera as stated earlier. Plottera offers pay-as-you drive and smart insurance solutions to insurance companies with a focus on optimizing fleet and work processes to help its customers reduce cost and increase profits. The company from its operations is able to generate, but not limited to, real-time data on the following:

1. Driving time (day or night);

2. Driving speed on different road conditions;

3. Driving behavior;

4. Breaks or stoppages in-between journeys;

5. Driving mileage reports;

6. Total trips made.

\subsubsection{Software}

The partner solutions company, Plottera, houses data and other resources from the Plottera web interface and applications which can easily be transmitted to insurance systems via APIs. Figure 7 shows the likely relationship in the ecosystem when telematics is introduced into the network.

\section{Customer Interaction(illustrative)}

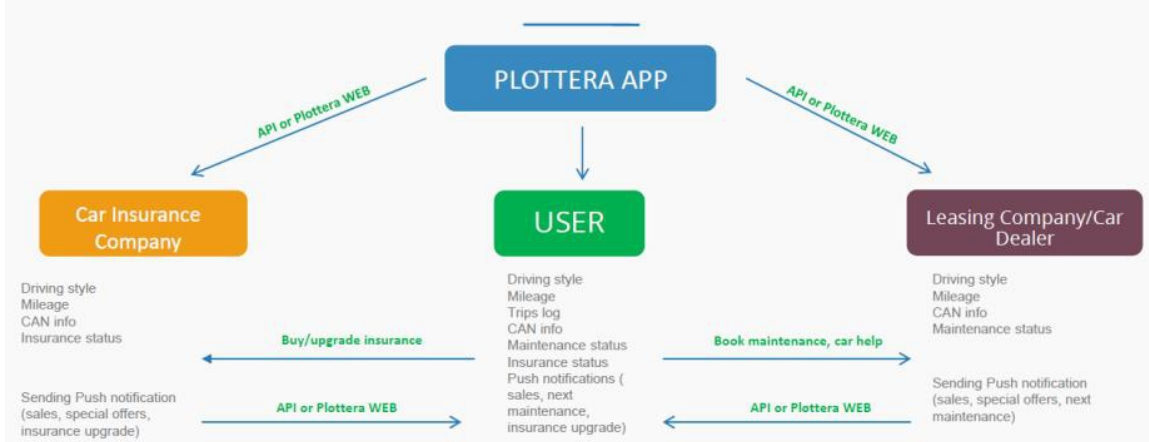

Figure 7. Illustration of the Plottera interface and applications. Source: Authors 
The interface generates real-time notifications which the vehicle driver also sees instantaneously. Figure 8 and 9 shows sample notification and the Plottera data distribution scheme.

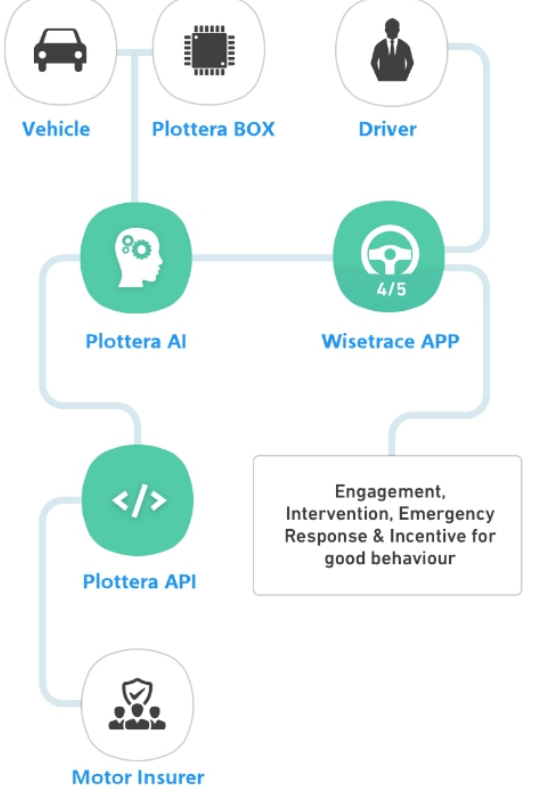

Figure 8. Plottera Data Distribution Scheme

Plottera $\cdot$ now

Medium risk

You are parked on medium risk area (Narrow parking spots)

Figure 9. Sample of Notification

A mobile application from Plottera informs drivers in parking spots about the risks that may arise. For example, narrow parking spaces is based on the real width of the client's car (illustrated in Figure 8), or about a place with a high risk of theft, among others. Intelligent notifications from the plotters are dynamic and they work only under certain conditions (specific time, location, etc.). Therefore, the driver receives only relevant and important notifications.

The Plottera database consists of 350,000 accident cases in Estonia. Based on algorithms written for this purpose, various areas in Estonia have been zoned and risk calculations have been undertaken using machine learning systems and tools. In addition, the various zones based on analytics have been classified as either low, moderate, high or extreme, per every $100 \mathrm{~m}^{2}$ in Estonia. The premise of the classifications included data on driving behavior (braking, acceleration, cornering, location, weather conditions and other events in the area). Others include rush hour feeds, narrow parking spots and 
wild animal locations, etc. Figure 10 shows the different risk zones based on Plottera analytics.

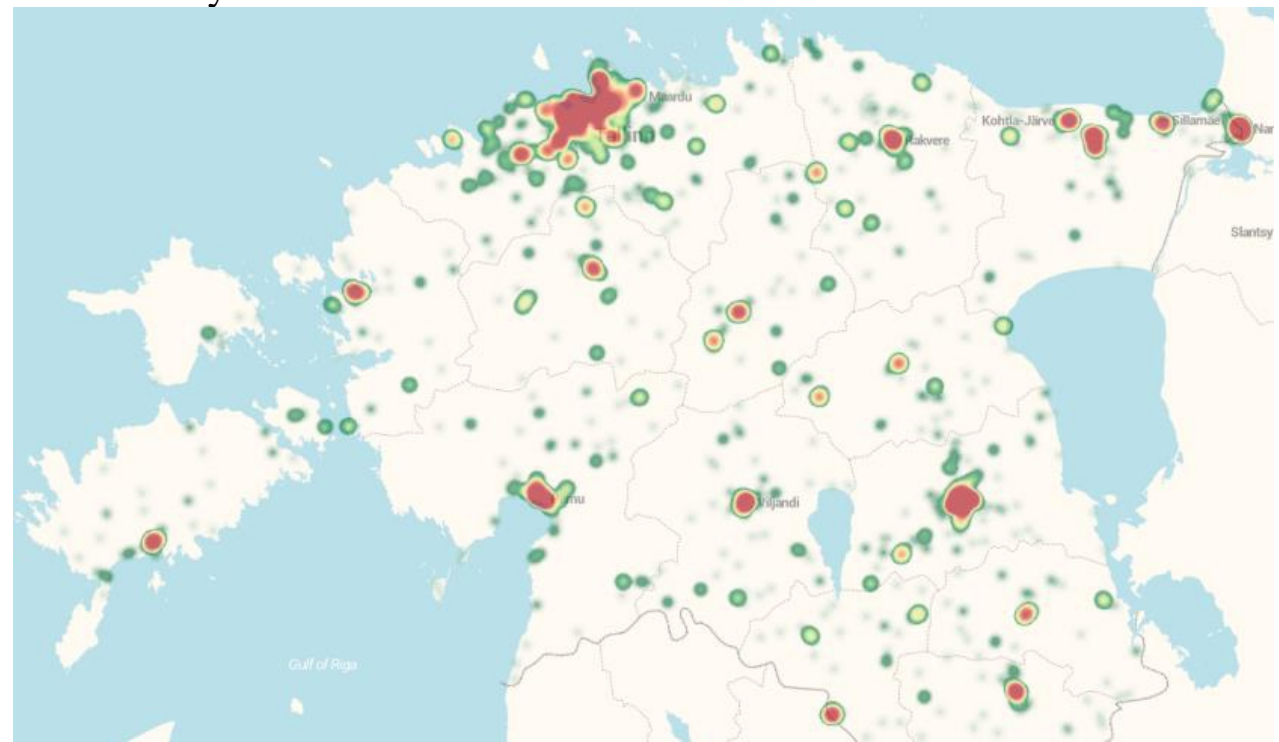

Figure 10. Risk zones based on Plottera analytics. Source: Authors

\subsubsection{Devices}

To collect data from the vehicles selected, GPS tracker, Teltonika FM1010, and FM1000 were employed. The reason for using these devices is that, firstly, the price is not high and insurance companies can invest their own resources in obtaining same. Secondly, the use of two different types of loggers allows for a wider scope of options between smart GPS and simple GPS. The third reason is that vehicle diagnostics data can easily be read as these devices use the modern GPS systems. For example in Russia, the Global Navigation Satellite System (GLONASS)/GPS -module with enhanced sensitivity is used; in Europe generally, the Galileo is commonly used; in China - BeiDou; in India - Indian Regional Navigation Satellite System (IRNSS); and in Japan - Quasi-Zenith Satellite System (QZSS) (Parkinson \& Spilker, 1996). Extensive studies have been conducted about automotive telematics types, fleet management, telematics security, GPS, remote diagnostics including the built-in diagnostic system (OBD2); sensors, satellite navigation and data transmission (see Minter, 2017; Hobba, 2016; Parkinson \& Spilker, 1996 as cited in Paefgen et al., 2013; Fleming, 2001; Dietz, 2007; Angelovič \& Jablonický, 2014; McLoad, 2005; and Heijden \& Marchau, 2002).

\subsubsection{Criteria for Selection of Vehicles}

Based on LKF data, 5 vehicles were selected from different risk groups, in an initial pilot project assessment. The list of vehicles was narrowed 
to 3 after careful consideration in order to cover adequately, all risk segments.

Table 1 shows the details of the 3 selected vehicles for the tests.

\section{Table 1. Car List for the Test}

\begin{tabular}{ccccc}
\hline Car Type & Car Manufacturer and Model & Engine Power & Year & Risk by LKF \\
\hline SUV & BMW X5 & $230 \mathrm{~kW}$ & 2017 & 6,91 \\
\hline Small Car & Mazda 2 & $94 \mathrm{~kW}$ & 2015 & 5,5 \\
\hline Small Car & Volkswagen Passat & $110 \mathrm{~kW}$ & 2016 & 4,54 \\
\hline
\end{tabular}

${ }^{1}$ Risk by LKF - Density of car accidents. This means that every X car out of 100 were involved in accidents (adapted based on LKF 2016 report).

\subsection{Test of Insurance-Oriented Telematics Technology}

4.8.0 Results of Tests

\begin{tabular}{cccccc}
\hline $\begin{array}{c}\text { Car Manufacturer and } \\
\text { Model }\end{array}$ & $\begin{array}{c}\text { Engine } \\
\text { Power }\end{array}$ & Year & $\begin{array}{c}\text { Risk by } \\
\text { LKF }^{1}\end{array}$ & $\begin{array}{c}\text { Driving Score from } \\
\text { Plottera }^{2}\end{array}$ & $\begin{array}{c}\text { Distance } \\
(\mathrm{km})\end{array}$ \\
\hline BMW X5 & $230 \mathrm{~kW}$ & 2017 & 6,91 & 6,2 & 6754 \\
\hline Mazda 2 & $94 \mathrm{~kW}$ & 2015 & 5,5 & 8,2 & 3710 \\
\hline Volkswagen Passat & $110 \mathrm{~kW}$ & 2016 & 4,54 & 6,7 & 7940 \\
\hline
\end{tabular}

Table 2. Consolidated results of test
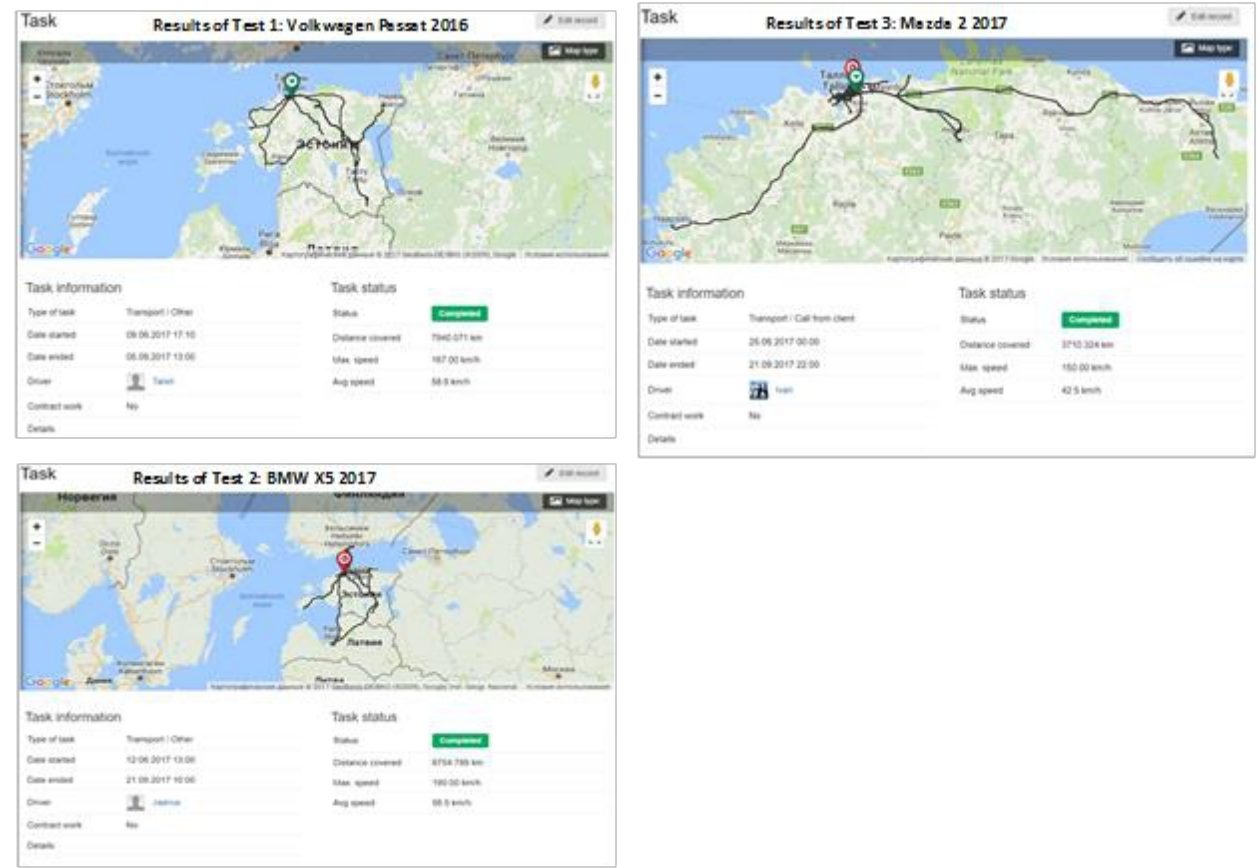

Figure 11. Summary of vehicle data from Plottera

4.8.1 Vehicle 1: Volkswagen Passat 2016

The pilot project period with Volkswagen Passat was 09.06.2017 17:11 - 5.09.2017 13:00.

Figure 11 summarizes results about vehicle 1. Total distance covered by Volkswagen Passat during the pilot project was 7,940 km. The maximum 
speed was $167 \mathrm{~km} / \mathrm{h}$ and the average speed was $58.6 \mathrm{~km} / \mathrm{h}$ for speed statistics. The average speed indicates that the car was driving around $60 \%$ of total time out of city. 49 cases of high levels of speeding above the maximum allowed speeds in Estonia were recorded, while the average speed of $50 \mathrm{~km} / \mathrm{h}$ indicated low risk speed.

Trip duration of more than $80 \%$ was less than 1 hour. This duration of trips is optimal, at which the probability of accidents due to fatigue is minimal. In addition to trip duration, trip distance was also optimal. The risk of accidents was low. The test results show that vehicle 1 was driven at high risk times in summer between 16:00 and 18:00 hours. The most trips occurred on work days. Wednesdays recorded the highest number of trips (61 trips or $16.40 \%$ of all trips completed), while Saturdays recorded the lowest number (41 trips or $11.02 \%$ of all trips completed).

\subsubsection{Vehicle 2: BMW X5 2017}

The pilot project period with BMW X5 was 12.06.2017 13:00 21.09.2017 10:00.

Figure 11 summarizes results about vehicle 2. Total distance covered by BMW X5 during the pilot project was $6,754 \mathrm{~km}$. The maximum speed was $190 \mathrm{~km} / \mathrm{h}$ and the average speed was $56.5 \mathrm{~km} / \mathrm{h}$ for speed statistics. The average speed indicates that the car was driving around $57 \%$ of total time out of city. The vehicle travelled twice to Finland and Latvia. 85 cases of high levels of speeding above the maximum allowed speeds in Estonia were recorded, while the average speed of $50 \mathrm{~km} / \mathrm{h}$ indicated low risk speed.

Trip duration of more than $73 \%$ was less than 1 hour. This duration of trips is optimal, at which the probability of accidents due to fatigue is minimal. In addition to trip duration, trip distance was also optimal. The risk of accidents was low. The test results show that vehicle 2 was driven at high risk times in summer between 16:00 and 18:00 hours. The most trips occurred on work days. Fridays recorded the highest number of trips (83 trips or $15.84 \%$ of all trips completed) while Sundays recorded the lowest number (63 trips or $12.02 \%$ of all trips completed).

\subsubsection{Vehicle 3: 2016 Mazda 22017}

Figure 11 summarizes results about vehicle 3 . Total distance covered by Mazda 2 during the pilot project was $3,710 \mathrm{~km}$. The maximum speed was $150 \mathrm{~km} / \mathrm{h}$ and the average speed was $42.5 \mathrm{~km} / \mathrm{h}$ for speed statistics. The average speed indicates that the car was driving around $90 \%$ of total time out of city. 19 cases of high levels of speeding above the maximum allowed speeds in Estonia were recorded, while the average speed of $50 \mathrm{~km} / \mathrm{h}$ indicated low risk speed. 
Trip duration of more than $85 \%$ was less than 1 hour. This duration of trips is optimal, at which the probability of accidents due to fatigue is minimal. In addition to trip duration, trip distance was also optimal. The risk of accidents was low. The test results show that vehicle 3 was driven at high risk times in summer between 16:00 and 18:00 hours (24\% of total trips completed). The most trips occurred on work days. Saturday recorded the highest number of trips (59 trips or $17.25 \%$ of all trips completed), while Wednesdays recorded the lowest number (39 trips or $11.4 \%$ of all trips completed) for vehicle 3 .

Figure 11 presents Plottera driving score by weeks. During the tests, the driving score was increased in all cars. The highest change was $60 \%$ with Volkswagen, and the smallest 20\% with Mazda.

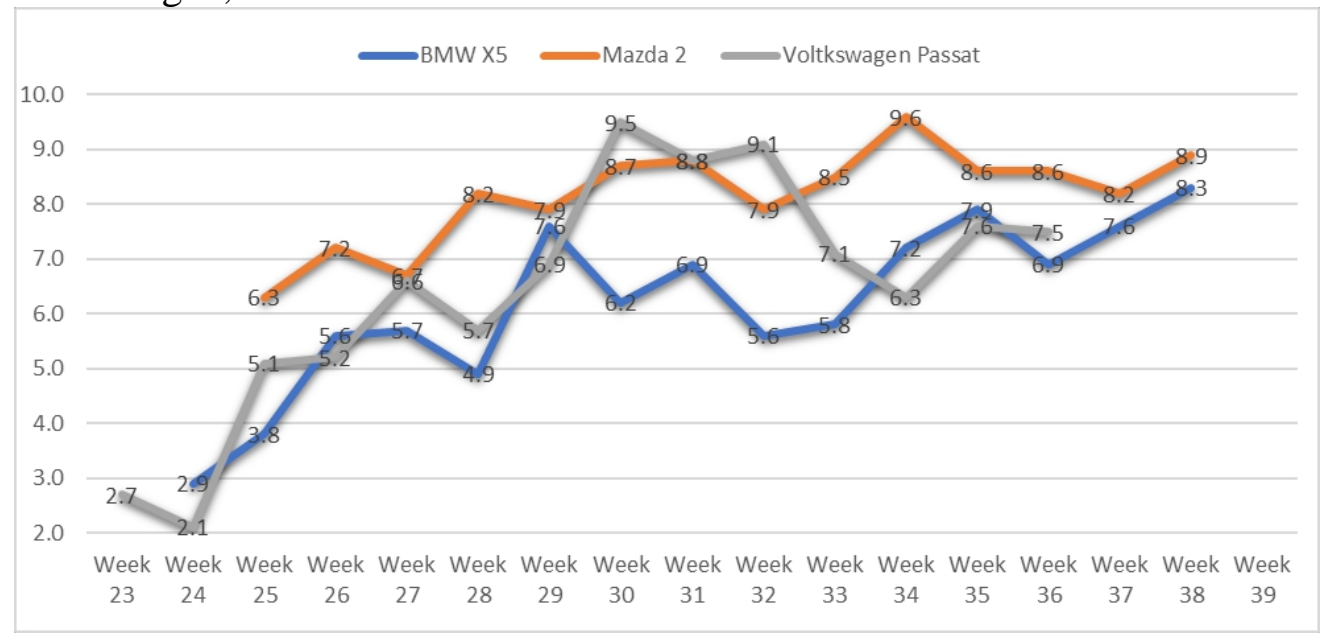

Figure 11. Test car Plottera driving score by weeks

\section{Discussion}

The primary research question is "How can telematics-oriented technology form an actor network for re-configuring the Estonian insurance ecosystem?" For this case study, we employ actor network theory as a lens and interpretation tool. ANT is used for analyzing the insurance ecosystem in Estonia as a trajectory of transformations, identifying stakeholders and their perspectives and interests throughout the process, and examining how these interests can be (or cannot be) aligned within a common goal to form a network of allies in agreement with the study of Tsohou, Karyda, Kokolakis, and Kiountouzis (2012). The authors also look to the main advantage of ANT in terms of providing a valuable analyzing instrument for exploring the role of various facets in socio-technical networks. The authors first show the ecosystem without telematics technology and the situation after telematics is brought into the picture and the findings is substantiated with data analyzed 
from actual tests conducted to address the following research questions in this study:

1. Who are the focal actors in the Estonian insurance ecosystem and how have they done so far?

2. What are the implications of re-configuring the insurance ecosystem with telematics technology?

ANT has been found to be a useful lens to explore the potential of telematics technology in Estonia as well as to examine its use in insurance field. This paper has studied stakeholder interactions with the telematics system by analyzing each in a temporary implementation project.

To tackle the first research question, the authors have shown that telematics technology, in the context of this research paper, is a focal actor and obligatory passage point (OPP). The representative actors are the Insured/Driver, Insurer, Motor Insurance Fund (LKF), Legislation (Act 2014) among others. As noted earlier in this paper, the original ecosystem is fraught with challenges, most of which have been exhausted earlier. The paper and our empirical analysis highlight the roles of each of the actants in the original network. Table 3 provides a summary of the main components of ANT theory (Heterogenous network; Tokens; Punctualization; OPP; Irreversibility; and Translation) as employed in this study to analyze the Estonian insurance ecosystem and the results of the study. The convergence provides the following potential outcomes of some confirming prior studies. It also extends theoretical contributions to this research stream, as detailed in Table 3, while also positing an answer to the second part of the first research question:

- Actor Network: It is a heterogenous network comprising of all the key players, the focal actor, OPP, and representative actors. Telematics technology was successful in re-aligning myraid elements in the original network during the tests on the vehicles.

- Tokens/Quasi Objects: These were not identified during the trials (See Table 3).

- Punctualization: It can be seen as a condition is met.

- Concept of Irreversibility: The changes telematics technology will introduce will re-configure, stabilize, and form an enduring network that can be sustained.

- The Translation Process: The translation process shows four phases to be walked through: problematization; intressement; enrollment; and mobilization. All conditions reviewed in prior literature and that are relevant to this study were analyzed and considered satisfactory. 


\begin{tabular}{|c|c|c|c|c|c|c|c|c|}
\hline \multirow[t]{4}{*}{$\begin{array}{c}\text { Translatio } \\
\mathbf{n}\end{array}$} & $\begin{array}{l}\text { Mobili } \\
n \text { Phas }\end{array}$ & \multicolumn{7}{|c|}{$\begin{array}{l}\text { Theory: This phase requires that the network is formalized and stabilized with all the } \\
\text { defined actors, their interests, and roles. } \\
\text { Result: As noted earlier, major policy and legislative amendments are required to } \\
\text { formalize this stage in Estonia. The tests revealed that this is feasible and will create } \\
\text { jobs for the solutions' start-ups in Estonia to thrive. }\end{array}$} \\
\hline & & \multicolumn{7}{|c|}{$\begin{array}{l}\text { Theory: Actors in this phase accept and align themselves with their allocated roles and } \\
\text { defined interests. } \\
\text { Result: This was adequately achieved during the pilot phase with the trials on the three } \\
\text { vehicles. Telematics reset and redefined roles of all Actants in the network. }\end{array}$} \\
\hline & & \multirow{2}{*}{\multicolumn{7}{|c|}{$\begin{array}{l}\text { Theory: The focal Actor initiates the process of locking the other actors into the } \\
\text { proposed roles in the new network. } \\
\text { Result: This condition was satisfied. (See Figure 6). } \\
\text { Theory: The focal Actor defines the nature of the problem in a specific situation with } \\
\text { other actors through negotiating about OPP in the forming network. } \\
\text { Result: Condition satisfied. }\end{array}$}} \\
\hline & & & & & & & & \\
\hline & & \multicolumn{7}{|c|}{$\begin{array}{l}\text { Theory: The concept of irreversibility states that the degree of irreversibility depends } \\
\text { on, first, the extent to which it is subsequently impossible to go back to a point where } \\
\text { translation was only among others and, second, the extent to which it shapes and } \\
\text { determines subsequent translations. } \\
\text { Result: Telematics technology will re-orient the insurance and financial technology } \\
\text { industries and therefore major changes, including policy and legislation, are required to } \\
\text { satisfy this condition. }\end{array}$} \\
\hline OP & & \multicolumn{7}{|c|}{$\begin{array}{l}\text { Theory: The focal Actor defines the OPP through which all other Actors must pass and } \\
\text { by which focal Actor becomes indispensable (Callon, 1986). } \\
\text { Result: The Focal Actor, Telematics, and its allied forces becomes the OPP in the trials, } \\
\text { satisfying this condition. }\end{array}$} \\
\hline & & \multicolumn{7}{|c|}{$\begin{array}{l}\text { Theory: Punctualization in ANT is when, within the domain, every actor in the web of } \\
\text { relations is connected to others and as a whole will be considered as a single object or } \\
\text { concept. ANT requires all Actors or sections of the network to perform required tasks } \\
\text { and thus maintain the web of relations. } \\
\text { Result: All other Actors, besides the OPP are considered representative Actors in the } \\
\text { network and therefore played varied roles during the trials, satisfying the } \\
\text { punctualization condition in ANT. }\end{array}$} \\
\hline & & \multicolumn{7}{|c|}{$\begin{array}{l}\text { Theory: Tokens are created through the successful interaction of actors/actants in a } \\
\text { network and are passed between Actors within the network. These token, as they are } \\
\text { increasingly transmitted or passed through the network, become punctualized and } \\
\text { materialized (Wickramasinghe, et al., 2012). } \\
\text { Result: During the trials, no such tokens were identified. It is suggested that quasi } \\
\text { objects may include premiums, which are generated as a result of risk profiles based on } \\
\text { telematics data. }\end{array}$} \\
\hline & & \multicolumn{7}{|c|}{$\begin{array}{l}\text { Theory: Heterogenous networks have been defined by Latour }(1996,2005) \text { and } \\
\text { Wickramasinghe, et al. (2012) as a network of materially heterogenous actors that is } \\
\text { achieved by a great deal of work that shapes those various social and non-social } \\
\text { elements and "disciplines" them so that they work together, instead of "making off on } \\
\text { their own". } \\
\text { Result: Telematics technology re-configured myriad elements in the original network, } \\
\text { during the trials on the vehicles. }\end{array}$} \\
\hline $\begin{array}{l}\text { Descr } \\
\mathrm{n}\end{array}$ & & & $\begin{array}{l}\text { Represent } \\
\text { ative } \\
\text { Actor }\end{array}$ & $\begin{array}{l}\text { Represent } \\
\text { ative } \\
\text { Actor }\end{array}$ & $\begin{array}{l}\text { Represent } \\
\text { ative } \\
\text { Actor }\end{array}$ & $\begin{array}{l}\text { Represent } \\
\text { ative } \\
\text { Actor }\end{array}$ & $\begin{array}{l}\text { Represent } \\
\text { ative } \\
\text { Actor }\end{array}$ & $\begin{array}{l}\text { Represen } \\
\text { tative } \\
\text { Actor }\end{array}$ \\
\hline $\mathbf{A}$ & & $\begin{array}{l}\text { Telema } \\
\text { ic } \\
\text { Techno } \\
\text { ogy }\end{array}$ & Legislati & $\begin{array}{l}\text { Insured/ } \\
\text { Driver }\end{array}$ & $\begin{array}{l}\text { The } \\
\text { Minister } \\
\text { (oversigh }\end{array}$ & & Insurer & $\begin{array}{l}\text { Motor } \\
\text { Insuranc } \\
\text { e Fund } \\
\text { (LKF) }\end{array}$ \\
\hline
\end{tabular}

Table 3. Telematics technology meets insurance in Estonia 
The second research question is addressed under Research Implications below. The authors look to Policy and other Practical Implications that could change the entire landscape of the Estonian insurance ecosystem.

\section{Implications for Practice}

The traditional motor insurance does not consider the driving behavior of the customer, which does not allow assess objectively to the risk of using each particular vehicle. Accordingly, there is no possibility to provide the optimal cost of insurance for a specific customer. Further, the asymmetry of the information between all actors in the network is more likely. Moreover, clients of traditional vehicle insurance coverage generally have three touch points with their insurers: when signing-off a coverage policy; when cancelling such policies; and after an insured event or accident, in case of claims. Using telematics, there are modifications in this customer interaction model: clients may regularly login to their coverage portal or use an application provided via their insurers that allows them to see their ultimate journeys or current driving behavior (Carbone, 2016b). This integrative approach to insurance provides safety nets for providers to be able to differentiate their products and services and make a positive impact on their clients rather than just serving as a point of registration for coverage, bill conveyance, and other peripheral activities in the chain. Furthermore, insurance companies that use telematics stand to gain exceptional precision and enhanced accuracy in data management, while significantly reducing information asymmetry due to interaction with telematics data and platforms.

In addition to the foregoing, telematics solutions offer insurance companies the opportunity to tailor-make insurance solutions, products, and services that respond to actual conditions in the environment, instead of hypothesized methods. Driving behavior and other data could inure to the design of reasonable discount schemes, reduction of insurance premiums based on lower risks profiles, and a more accurate usage- based mechanisms for arriving at calculations of premiums due. Customer data algorithms could be designed for specific markets and these algorithms and models can be dynamically updated. This was done as a result of geo-specific functions, which is a feature that is non-existent in the traditional insurance package offerings. Such companies, still offering traditional products with the deployment of this technology on a full scale, stand to become marginalized and irrelevant because customers are more likely to switch to enjoy packages based on more intelligent technology solutions and meet their personal needs and preferences. 
Therefore, the study points to the benefits and opportunities (summarized) of deploying insurance-oriented telematics technology in the Estonian insurance ecosystem, as follows:

1. The ability to create new products based on the principles of insurance telematics Pay-As-You-Drive and Pay-How-You-Drive calculation pricing schemes and, therefore, customize offerings and tariff plans for each client based on accurate individual risk accounting and profiling methods using telematics. It is also likely that more companies will enroll their fleets with the design of tailor-made offering to meet such specific demand.

2. An increased probability for the Insurer to establish fault; determine insurance fraud and cut out revenue losses based on false information sometimes provided about the insured event; reduce cycle times in claims processing.

3. Enhanced communication and engagement between the Insured and Insurer via mobile applications.

Silvello (2016) observed in a similar study that the foregoing factors could contribute to increased profits for the Insurer. In addition to that benefit, there is the possibility of attracting new customers. Meanwhile, insurance companies can focus on risk mitigation as noted earlier when onboarding new clients or when updating insurance policies.

On the Insured side, the following gains can be obtained. These include: personal control over cost of insurance; transparency of pricing and calculation mechanisms, and possibly bonuses for good driver behavior and loyalty; Improved and safer driver behavior, reducing frequency and severity of accidents; instant interaction with insurance stakeholders about an insured event, so that the driver or passers-by may not need to necessarily contact these agencies under such traumatic conditions; reduction in fuel consumption and potential decrease in automobile wear and tear.

\subsection{Social Implications}

The Estonian social set-up stands to gain from the re-configuration of the insurance ecosystem. These can be considered from several perspectives.

Firstly, from the general social system, telematics technology, when employed, could increase road and traffic safety due to improved driver behavior and efficient tracking and recovery of vehicles. This means enhanced levels of citizen and pedestrian safety, lower social expenses, and lower life losses. According to the World Health Organisation (WHO), technologyassisted and autonomous driving will cut frequency and costs of road accidents (WHO, 2015). Furthermore, the millions of euros paid out for accidents and other insured occurrences could be reduced. For example, the 87.1 million euros in payments recorded by the LKF for just cases at intersections, over 
2009 to 2016, could be halved or reduced to less than 30\%, culminating in saving to the state, which can be channeled into other development activities. The ANIA has resoundingly noted that the use of smart devices could drop motor insurance claims by $15-25 \%$ (ANIA, 2016).

Environmentally, $\mathrm{CO}^{2}$ emissions will be lowered on one end with a reduction in fuel consumption, allowing for a cleaner environment overall.

Some of the gains to the Estonia besides the many economic benefits and gains enumerated earlier, include political gains such as virtual violation detection and instant notification about deviant behavior to relevant stakeholders as well as a connected law enforcement organization, who can also call for policy and other legislative amendments to improve other laws not only about vehicles and vehicular arrangements, but also about driver licensing regimes and laws. Jobs could also be created for many software and application developers and technology companies in Estonia and beyond, who would drive further innovation for the insurtech and fintech industries, sector, and the country.

\section{Research Limitations and Future Research}

The authors consider some key limitations to the study.

Firstly, the role of researchers has been acknowledged to impact the actor-network and its conceptualization (Cresswell et al., 2011), which may limit the generalizability of the findings. In any case, the study is focused within a particular context.

Secondly, the findings from the study may be considered exploratory since the implementation of the telematics technology on the three vehicles are not entirely representative of the causal factors discussed in the paper and the results of the test thereof. ANT has received criticisms for the lack of explanatory or critical power (Cresswell, et al., 2010; Mitev, 2009). The idea of using ANT in combination with other theories has been suggested (Cresswell, et al., 2011; Greenhalgh \& Stones, 2010; Mitev, 2009), which could add a more critical lens to ANT theory. Further empirical confirmatory research is required to cover aspect of this research stream not addressed in this study.

\section{Conclusion}

In this paper, the specific case of the Estonian insurance ecosystem was analyzed from the theoretical perspective of ANT. Since the aim was to contribute to the current discourse on the application of ANT to the field of information systems, the concluding section of the paper discusses the analysis and delves into specific aspects of how ANT can be applied. Also, it extends established applications of ANT-related concepts while bringing out interconnections. The insurtech and fintech landscapes are evolving really 
fast, and Estonia cannot be left behind this wind of technological inertia that is blowing over the European region. Scholars and practitioners alike propose that successful transitions to new solutions, such as that suggested in this paper, should be accompanied by a deep understanding of technology and detailed analysis of the processes and policy and legislative changes, which are feasible given the transactional cost of implementing such projects in the society. The Estonian society has seen many technological amendments since re-independence in agreement with the studies of Sai, et al. (2017). The potential result of using telematics will be the emergence of new players in the Estonian financial markets who are more technology-oriented with deeper understanding of its associated risks. Lastly, the use of telematics will bring to the fore the subject of Big Data, which will mean better infrastructure and equipped personnel to deal with it. The records show, as at end of 2015, that $29 \%$ of Estonian enterprises have vast experience in big data analysis of information and communication, and $21 \%$ in financial and insurance data analysis (Sai, et al., 2017, p. 6). Therefore, these percentages could markedly move up.

\section{References:}

1. Angelovič M. \& Jablonický, J. (2014). The Effect of Alternative Fuel on the On-Board Diagnostics System at Compression-Ignition (Diesel) Combustion Engines. 2014, p 358.

2. ANIA (2016). How the connected world is changing the insurance business: Lessons from Italy, in Insurance Analytics Europe Summit. $\begin{array}{llll}\text { Retrieved } & 01 & 24, & 2016\end{array}$ http://www.ania.it/export/sites/default/it/pubblicazioni/monografie-einterventi/Dario-Focarelli_Londra_5_6_ottobre.pdf

3. Azzopardi, M. \& Cortis, D. (2013). Implementing automotive telematics for insurance covers of fleets. Journal of Technology Management and Innovation, 8(4), 5967. https://doi.org/10.4067/S0718-27242013000500005

4. Baecke, P. \& Bocca, L. (2017). The value of vehicle telematics data in insurance risk selection processes. Decis. Support Syst. 98(C), 69-79.

5. Bijker, W.E., Hughes, T.P., \& Pinch, T.J. (Eds) (1987). The Social Construction of Technological Systems: New Directions in the Sociology and History of Technology, MIT Press, Cambridge, MA.

6. Callon, M. (1986). Some elements of a sociology of translation: domestication of the scallops and the fishermen of St Brieuc Bay. In J. Law(Ed.), Power, action and belief: A new sociology of knowledge? (pp. 196-223). London: Routledge.

7. Carbone, M. (2016b). Connected Insurance Observatory - The future of insurance is Insur- tech. Retrieved 01 27, 2016 
from https://www.linkedin.com/pulse/future-insurance-insurtechmatteo-carbone/

8. Chehui, Zhangjiwu, \& Zhangxingyang (2011). Research on motor vehicle insurance underwriting risk management model. Procedia Engineering, 15 , 4973-4977. https://doi.org/10.1016/j.proeng.2011.08.924

9. Cressman, D. (2009). A brief overview of actor network theory: Punctualization, heterogeneous engineering \& translation. Vancouver: ACT Lab/Center for Policy Research on Science \& Technology (CPROST) School of Communication, Simon Fraser University (Working Paper).

10. Cresswell, K., Worth, A., \& Sheikh, A. (2011). Implementing and adopting electronic health record systems. Clinical Governance: An International Journal, 16(4), 320- 336. doi: doi:10.1108/14777271111175369

11. David, M. (2015). A Review of Theoretical Concepts and Empirical Literature of Non-life Insurance Pricing. Procedia Economics and Finance, 20(15), 157-162. https://doi.org/10.1016/S22125671(15)00060-X

12. David, M. (2015). Auto Insurance Premium Calculation Using Generalized Linear Models. Procedia Economics and Finance, 20(15), 147-156. https://doi.org/10.1016/S2212-5671(15)00059-3

13. Dietz, U. (2007). Turning eCall into a basis for future telematic services. Paper presented at the 14th World Congress on Intelligent Transportation Systems. [Online]. https://trid.trb.org/view/883532

14. Dudoskiy, J. (2018). The Ultimate Guide to Writing a Dissertation in Business Studies: A Step-by-Step Assistance, Researchmethodology.net

15. Estonian Traffic Insurance Fund (LKF) Reports (2016) (2017). Available [online] https://www.lkf.ee/et

16. Fleming, W. J. (2001). Overview of Automotive Sensors. IEEE Sensors Journal, 1(4), pp. 296-308.

17. Heijden van der, R. \& Marchau, V. (2002). Innovating road traffic management by ITS: a future perspective. International Journal of Technology, Policy and Management, vol. 2, no. 1, pp. 20-39, 2002.

18. Husnjak, S., Peraković, D., Forenbacher, I., \& Mumdziev, M. (2015). Telematics system in usage based motor insurance. Procedia Engineering, 100(January), 816825. https://doi.org/10.1016/j.proeng.2015.01.436

19. Iwan, S. (2016). 'Implementation of telematics-based good practices to support urban freight transport systems, applying a city's adaptability level', Int. J. Shipping and Transport Logistics, Vol. 8, 
No. 5, pp.531-551.

20. Latour, B. (1999). Pandora's Hope: Essays on the Reality of Science Studies, Harvard University Press, Cambridge, MA.

21. Latour, B. (2006). Reassembling the Social. Politica y Sociedad (Vol. 43). https://doi.org/10.1163/156913308X336453

22. Lee, I. \& Shin, Y. J. (2017). Fintech: Ecosystem, business models, investment decisions, and challenges. Business Horizons. https://doi.org/10.1016/j.bushor.2017.09.003

23. Ma, Y-L., Zhu X., Hu, X., \& Chiu, Y-C. (2018). The use of contextsensitive insurance telematics data in auto insurance rate making. Transportation Research Part A: Policy and Practice, 113, 243-258. DOI: $10.1016 /$ j.tra.2018.04.013

24. Mintsis, G., Basbas, S., Papaioannou, P., Taxiltaris, C., \& Tziavos, I. N. (2004). Applications of GPS technology in the land transportation system. European Journal of Operational Research, vol. 152, no. 2, pp. 399-409.

25. Mitev, N. (2009). In and out of actor-network theory: a necessary but insufficient journey, Information Technology \& People, Vol. 22 No. 1, pp. 9-25.

26. Motor Insurance Act (2014 amended). Estonia. Available [online] https://www.riigiteataja.ee/en/eli/506012015001/consolide

27. Nijkamp, P., Pepping, G., \& Banister, D. (1996). Telematics and Transport Behavior. New York (USA): Springer.

28. Nora, S. \& Minc, A. (1978). L'informatisation de la société. Paris (France): Documentation française cited in Ippisch, T. (2010). Telematics Data in Motor Insurance: Creating Value by Understanding the Impact of Accidents on Vehicle Use. Framework, (3829), 187.

29. Papadopoulos, T. (2007). Constructing and translating a sociotechnical innovation using Actor Network Theory. 16th EDAMBA Summer Academy, Soreze, France.

30. Peppard, J., Edwards, C., \& Lambert, R. (2011). MIS Quarterly Executive. MIS Quarterly, 10(2), 115-117. https://doi.org/10.1108/02635570910926564

31. Pulk, K. \& Murumägi, M. (2013). The Network of Different Actors Influencing the Process of Urban Planning and Development - The Case of Tallinn City Hall, Journal of Management and Change, EBS (30).

32. Rejikumar, G. (2013). A pre-launch exploration of customer acceptance of usage based vehicle insurance policy, IIMB Management Review, 25(1), 19-27. [online] https://doi.org/10.1016/j.iimb.2012.11.002 
33. Sai Andrew, A. \& Boadi, P. (2017). A Bundled Approach to Explaining Technological Change: The Case of e-Estonia, European Journal of Business and Management [online] http://iiste.org/Journals/index.php/EJBM/article/view/39126

34. Segovia-Vargas, M.J., Camacho-Minano, MDM., \& Pascual-Ezama, D. (2015). Risk factors selection in automobile insurance policies: a way to improve the bottom line of insurance companies. Review of Business Man- agement, 17, 1228-1245. doi:10.7819/rbgn.v17i57.1741.

35. Shim, Y. \& Shin, D. H. (2016). Analyzing China's Fintech Industry from the Perspective of Actor-Network Theory. Telecommunications Policy, 40(2-3), 168181. https://doi.org/10.1016/j.telpol.2015.11.005

36. Silvello, A. (2016). The three pillars of connected insurance. Retrieved 01 27, 2016 from http://harvardecon.org/?p=3310

37. McLoad, T. (2005). Fleet Management Systems: e Future is Here, Fleet Owner.

38. Troncoso, C., Danezis, G., Kosta, E., \& Preneel, B. (2007). Pri- payd: privacy friendly pay-as-you-drive insurance. Proceedings of the 2007 ACM workshop on Privacy in electronic society, (pp. 99-107). doi:10.1145/1314333.1314353.

39. Tsohou, A., Karyda, M., Kokolakis, S., \& Kiountouzis, E. (2012). Analyzing trajectories of information security awareness. Information Technology \& People, 25(3), 327352. https://doi.org/10.1108/09593841211254358

40. Van Der Laan, J. D., Heino, A., \& De Waard, D. (1997). A simple procedure for the assessment of acceptance of advanced transport telematics. Transportation Research Part C: Emerging Technologies, 5(1), pp. 1-10.

41. Walker, G. \& Manson, A. (2014). 'Telematics, urban freight logistics and low carbon road networks', Journal of Transport Geography, Elsevier, Vol. 37, pp. 74-81.

42. Wickramasinghe, N., Tatnall, A., \& Goldberg, S. (2012). Understanding the Advantages of Mobile Solutions for Chronic Disease Management: The Role of ANT as a Rich Theoretical Lens. International Journal of Actor-Network Theory and Technological Innovation (IJANTTI), 4(1), 12.

43. World Health Organization (WHO) (2015). Road Safety. Fact Sheet, $\begin{array}{llll}\text { Retrieved } & 09 & 25, & 2016\end{array}$ from http://www.wpro.who.int/mediacentre/factsheets/fs_20130627/ en/

44. Xu, L. D., He, W., \& Li, S. (2014). Internet of things in industries: 
survey. IEEE Transactions on Industrial Informatics, 10, 2233-2243. doi:10.1109/TII.2014.2300753.

45. Young, D., Borland, R., \& Coghill, K. (2010). An actor network theory analysis of policy innovation for smoke-free places: understanding change in complex systems. American public Health, 7(100), 12081217, http://dx.doi.org/10.2105/AJPH.2009.184705.

46. Zhang, D., Ivanco, A., \& Filipi, Z. (2015). 'An averaging approach to estimate urban traffic speed using large-scale origin-destination data', Int. J. Powertrains, Vol. 4, No. 2, pp.126-140. 